\title{
A indisciplina de Fernanda Arêas Peixoto
}

\author{
[ The indiscipline of Fernanda Arêas Peixoto
}

\section{Rodrigo Ramassote ${ }^{\mathrm{I}}$}

\section{Luís Felipe Sobral ${ }^{2}$}

[ PEIXOTO, Fernanda Arêas. A viagem como vocação. Itinerários, parcerias e formas de conhecimento. São Paulo: Fapesp/Edusp, 20I5, 288 p.

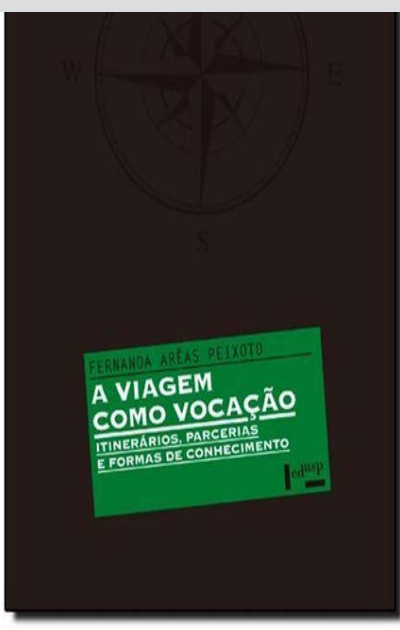

A publicação de A viagem como vocação, apresentado originalmente em 2012 como tese de livre-docência ao Departamento de Antropologia da Universidade de São Paulo (USP), representa, a um só tempo, uma retomada e um aprofundamento de temas, autores e questões teórico-metodológicas que pontilham a trajetória intelectual da antropóloga Fernanda Arêas Peixoto. Desde a sua dissertação de mestrado, Estrangeiros no Brasil: a Missão Francesa na Universidade de São Paulo (MASSI, I99I), orientada por Mariza Corrêa, defendida em I99I na Universidade Estadual de Campinas (Unicamp) e nunca editada na íntegra, mas parcialmente publicada em capítulos de livro e artigos de periódicos, Peixoto tem se preocupado com a circulação e o intercâmbio de paradigmas intelectuais, práticas científicas, pesquisadores e acordos de cooperação técnica que articulam redes acadêmicas transatlânticas envolvendo o Brasil e tradições intelectuais estrangeiras - notadamente a da França e a dos EUA.

RAMASSOTE, Rodrigo; SOBRAL, Luís Felipe. A indisciplina de Fernanda Arêas Peixoto. Revista do Instituto de Estudos Brasileiros, Brasil, n. 70, p. 297-304, ago. 2018.

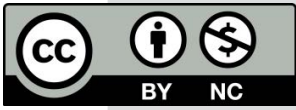

DOI: http://dx.doi.org/Io.II606/issn.23I6-90IX.voi70p297-304

I Universidade de São Paulo (USP, São Paulo, SP, Brasil).

2 Universidade de São Paulo (USP, São Paulo, SP, Brasil). 
Assim é que, no âmbito do projeto sobre a história das ciências sociais no Brasil, coordenado por Sergio Miceli no Instituto de Estudos Econômicos, Sociais e Políticos de São Paulo (Idesp), ela esquadrinhou as principais características e motivações da presença de franceses e norte-americanos no país, entre as décadas de I930 e I960: contexto formativo originário, etapa da carreira, tempo de permanência, modalidades de inserção institucional, padrões de relação intelectual e interesses investigativos de seus participantes (MASSI, I989). Desse diagnóstico geral, a autora ressalta a importância fundamental da vinda de missões científicas e de profissionais estrangeiros para a definição e divulgação de modelos teórico-metodológicos, programas e projetos de pesquisa, recortes temáticos e objetos de investigação, e a repercussão que tiveram na definição de fronteiras disciplinares e no processo de profissionalização das ciências sociais brasileiras.

De igual maneira, a curta temporada acadêmica brasileira de Claude Lévi-Strauss, durante a segunda metade da década de I930, na então recém-inaugurada Faculdade de Filosofia, Ciências e Letras (FFCL) da USP, foi objeto de escrutínio em suas dimensões profissionais e repercussões intelectuais (PEIXOTO, I998). Em consonância com o juízo emitido por etnólogos brasileiros, que destacam a contribuição marcante desse período nas obras do autor das Mitológicas, Peixoto enfatiza os desdobramentos dessa passagem curta, mas decisiva, para a futura carreira do etnólogo francês - a despeito, inclusive, das diatribes registradas por ele em Tristes trópicos (LÉVI-STRAUSS, I955). Por fim, Peixoto espreitou o tema da viagem e sua centralidade na constituição do ofício do antropólogo, por meio do confronto de Tristes trópicos, de Lévi-Strauss, e de A África fantasma, de Michel Leiris (I934), nos quais anotações de campo, fragmentos literários, esboços interpretativos se confundem em duas peças narrativas inclassificáveis (MASSI, I992). Ela debruçou-se novamente sobre o livro de Leiris para redigir a apresentação de sua tradução brasileira (PEIXOTO, 2007).

Em sua tese de doutorado, Diálogos brasileiros: uma análise da obra de Roger Bastide (PEIXOTO, 2000), orientada por Paula Montero, defendida em I998 na USP e publicada em livro pela Edusp, Peixoto dedicou-se à leitura da vasta produção do sociólogo francês Roger Bastide, a partir da recuperação de suas interlocuções e parcerias com pesquisadores brasileiros - em particular, Mário de Andrade, Gilberto Freyre e Florestan Fernandes. Nos dezesseis anos de permanência entre nós, 
Bastide reformulou não apenas seus objetos de interesse e obsessões investigativas, precocemente esboçados na França, como também seu ponto de vista e suas interpretações sobre os mais variados fenômenos socioculturais dos trópicos por meio do contato com autores pertencentes a distintas tradições, linhagens e matrizes intelectuais. Para dar conta do caráter multifacetado e plural das intervenções de Bastide, Peixoto lançou mão da noção de "diálogos exemplares" como procedimento de análise, dispositivo que lhe permitiu simultaneamente qualificar com maior precisão o perfil e resguardar a heterogeneidade dessa produção.

Se na maior parte dos trabalhos resultantes da dissertação de mestrado a moldura institucional fornecia a ancoragem seja para a construção da tipologia comparada entre franceses e norte-americanos, seja para a sondagem da inflexão decisiva na carreira de Lévi-Strauss, Peixoto adotou no estudo sobre Bastide uma postura afinada com a própria natureza do conhecimento antropológico: a incorporação do ponto de vista nativo como fio condutor, ou plataforma de observação, na apreensão das linhas de força que fundamentam a obra bastidiana. Na introdução a Diálogos brasileiros, Peixoto reivindica que seu "método crítico" se inspira, de modo coerente, no "próprio Bastide", o qual por sua vez postulava o acompanhamento de temas obsessivos e reclamava o princípio de "refletores convergentes" na leitura de determinado autor. Lembra ainda que o sociólogo francês, ao longo de seus trabalhos, fez uso em diversas ocasiões do diálogo como forma expositiva e reflexiva. Por essa razão, Peixoto não se valeu de uma noção de contexto circunscrita ao "campo intelectual e às práticas sociais de seus atores", tampouco se aferrou ao exercício de uma leitura interna alheia a qualquer referência à trama do "tempo e do espaço" e desconectada de "homens e ideias”; para ela, a produção bastidiana adquire maior inteligibilidade à luz de parâmetros instituídos pela perspectiva advinda do próprio objeto de investigação.

Do ponto de vista temático, A viagem como vocação, livro finalista da edição 2016 do Prêmio Jabuti, recupera a problemática da viagem em suas diversas modalidades "viagens de estudo, pesquisa e formação; viagens de passeio e turismo; de descoberta e/ou reconhecimento; viagens exteriores (deslocamentos no espaço) e interiores (modificadoras do self); viagens livrescas e expedições científicas" (p. I2) - realizadas no Brasil, na América Hispânica e na África, entre as décadas de I930 e I960, por antropólogos, sociólogos e historiadores, com destaque para Roger Bastide, Gilberto Freyre, Pierre Verger e Michel Leiris. Peixoto recusa uma definição estrita de viagem, preferindo empregar o termo em sua acepção romântica, ou seja, "como aventura do corpo e do espírito, peregrinação renovadora e busca de fontes para a criação culta" (p. I2). Tal escolha não conduz apenas à consideração da viagem como uma forma de conhecimento; ela permite também vislumbrar a tensão decisiva entre profissão e vocação que permeia os vários percursos dos viajantes estudados no livro. Não se trata portanto de elaborar uma reflexão teórica sobre a viagem em geral, mas de "acompanhar alguns itinerários, indagando sobre a economia das viagens e sobre sua relação com a imaginação criadora” (p. I3), incluindo as formas diversificadas daí resultantes: "ensaios, artigos acadêmicos, textos jornalísticos, relatos de viagem, desenhos e fotografias" (p. I3). Por sua vez, tal diversidade de formas assinala o caráter multifacetado desses viajantes, que, se podem ser classificados como intelectuais, são considerados na mesma medida desenhistas, pintores, arquitetos e fotógrafos. 
No intuito então de apreender essas experiências de deslocamento espacial que o tempo consumiu, Peixoto privilegia, segundo sua própria expressão, o ateliê do criador, isto é, os materiais aparentemente menores produzidos ao longo das viagens e expurgados de seus objetos acabados: "correspondências, diários e escritos de ocasião; relatos e anotações; desenhos e fotografias” (p. 23). Não há, contudo, nesse procedimento nenhuma intenção de expor verdades ocultas de textos canônicos; pelo contrário: a autora debruça-se sobre esse tipo de material justamente para ampliar os sentidos de tais textos e, dessa maneira, interpelar o cânone de um ponto de vista diferente. Ao apresentar assim suas balizas analíticas, A viagem como vocação situa-se plena e declaradamente no debate entre a antropologia, que conduz Peixoto a tomar a viagem fundamentalmente como uma experiência de alteridade, e a história, em particular certa história de tradição francesa, representada por François Hartog, Michel de Certeau, Marcel Detienne e Jean-Pierre Vernant, que pensa a viagem como um operador reflexivo e narrativo, assinala a relação inextrincável entre práticas e enunciados e valoriza a dimensão artesanal do trabalho intelectual 3 .

A própria organização do livro orienta-se por tais balizas. A viagem como vocação compõe-se de seis capítulos divididos em duas partes, precedidos por uma introdução nomeada "Plano" e sucedidos por um posfácio do sociólogo Leopoldo Waizbort; o leitor encontra ainda duas pausas intercaladas entre as duas partes e a orelha assinada pela antropóloga Heloisa Pontes. A primeira parte, intitulada "Cartografias e miradas", começa com os percursos de Bastide pelas cidades brasileiras, especialmente São Paulo; Peixoto demonstra aí como ele apropriou-se de um vocabulário modernista para exercitar uma perspectiva barroca, isto é, descentrada, sobre o espaço urbano brasileiro, o que permitiu apreendê-lo em sua multiplicidade. Esse sentido alargado que Bastide conferiu ao barroco, mais que o estilo artístico próprio de uma época, um "fato da cultura - visão de mundo e sensibilidade", uma "explosão criativa capaz de interpelar criticamente a modernidade” (p. 69), retorna no segundo capítulo, dedicado aos estudos do sociólogo sobre o candomblé nordestino. O capítulo seguinte debruça-se sobre o aprendizado de Gilberto Freyre sobre a América Hispânica, realizado a princípio indiretamente, através de imagens do muralismo mexicano e das impressões de viagem do historiador e diplomata Oliveira Lima, depois por meio de uma viagem à Argentina, ao Uruguai e ao Paraguai em I94I. Tal aprendizado avança de modo comparativo não somente com o conteúdo das reflexões de Freyre sobre o Brasil, mas também com as formas empregadas por ele para expressá-las; a autora traz assim ao primeiro plano a questão do estatuto da imagem na obra do sociólogo, examinando tanto sua colaboração estreita com os desenhistas contemporâneos como a prolífica produção artística do próprio Freyre, que possuía um talento inegável 4 . Em seguida, a primeira pausa permite à autora voltar-se sobre

3 Vale observar que, em setembro de 20I6, Peixoto organizou na USP, junto com a antropóloga Julia Ruiz Di Giovanni, o colóquio Michel de Certeau [Em uso], que discutiu com inúmeros convidados os usos diversos feitos da obra desse historiador francês.

4 As imagens produzidas por Freyre foram objeto, entre março e julho de 20I6, no Recife e em São Paulo, da exposição Gilberto Freyre: vida, forma e cor, que Peixoto organizou com Jamille Barbosa, Leonardo Borges e Clarissa Diniz. 
os passos dados até aqui, destacando-se assim alguns pontos: a inseparabilidade entre o trabalho intelectual e as práticas cotidianas, a contaminação de feitios diversos de deslocamento espacial, a repercussão do conhecimento prévio na experiência da viagem, o descentramento de uma perspectiva unificada sobre o mundo.

A segunda parte, intitulada "Roteiros africanos", abre-se com um exame da questão do Brasil na África através da parceria, intelectual e afetiva, de Bastide e Pierre Verger, focando-se particularmente na viagem pelo Benim (então Daomé) e pela Nigéria que eles realizaram juntos em I958. Peixoto mostra como a descoberta da África por ambos foi mediada pela experiência brasileira, alterando o rumo da pesquisa africanista francesa, dirigida habitualmente ao mundo colonial; isso os levou a tomarem o Atlântico como unidade analítica, escapando portanto do recorte nacional empregado de praxe. $\mathrm{O}$ capítulo seguinte acompanha a viagem que Freyre realizou, entre I95I e I952, por Portugal e suas colônias de além-mar a convite do governo português. Aqui, como no outro capítulo dedicado a Freyre, a autora considera a viagem antes da viagem, que começa na verdade muito antes, com a leitura precoce de Camões, e impõe-se como um tema de interesse constante do sociólogo; em contrapartida, todo esse conhecimento acumulado e produzido previamente acabou subvertendo a experiência da alteridade, conforme Freyre buscava as "marcas luso-brasileiras na paisagem material, cultural e social” (p. I97). O último capítulo trata igualmente da viagem que precede a viagem, porém dessa vez a autora depara-se com a África em Paris: ela examina aí o repertório de ideias sobre a África de Leiris, que se encontra na iminência de partir pela primeira vez para esse continente como membro da Missão Etnográfica e Linguística Dacar-Djibuti, empreendida entre I93I e I933. Finalmente, a segunda pausa, que também faz as vezes de conclusão, fornece à autora a oportunidade de lançar um olhar retrospectivo sobre o trajeto percorrido nesses roteiros africanos; ela assinala então duas dimensões que, anunciadas anteriormente, ganham corpo nessa segunda parte: primeiro, o "lugar decisivo da amizade na produção do conhecimento e na criação de modo geral” (p. 245); segundo, a "importância da memória nas experiências de viagem" (p. 246).

Ao partir de um plano bem definido, capaz de traçar um percurso com paradas autorreflexivas, A viagem como vocação incorpora em sua forma o objeto mesmo de seu interesse. No entanto, tal planejamento não impede a intervenção frequente de uma tendência perambulatória que caracteriza as boas viagens; reside aí, sem dúvida, o ponto forte do livro, que, a despeito de se munir de coordenadas analíticas precisas, não as impõe aos seus viajantes, preferindo antes acompanhar seus itinerários diversos e extraindo daí não apenas a matéria, mas o próprio fundamento de sua interpretação. Em outras palavras, Peixoto procede, a exemplo de sua tese de doutorado, a uma espécie de mimetização de seu objeto de estudo. Esse recurso atinge seu paroxismo no último capítulo de $A$ viagem como vocação, que se intitula "O olho do etnógrafo" e cujo foco é o artigo homônimo de Leiris (I930). Tal artigo foi publicado no final de I930 na revista Documents, dirigida por Georges Bataille e na qual Leiris exercia a função de secretário; não obstante a presença assídua de dissidentes surrealistas, entre eles o próprio Leiris, a revista contava com colaboradores diversos e orientava-se pelo rompimento da hierarquia entre todos os tipos de objetos, fossem eles artísticos ou prosaicos, ocidentais ou oriundos de outras partes do 
mundo, valorizando sobretudo os usos diversos e concretos feitos deles. Na redação de Documents, realiza-se uma guinada decisiva na trajetória de Leiris: ele conhece aí o antropólogo Marcel Griaule, que, como chefe da futura Missão Dacar-Djibuti, convida-o a compor sua equipe. Diante da partida iminente, Leiris reflete então sobre as ideias que associa ao continente. Peixoto interessa-se especialmente por um procedimento caro à revista e empregado por Leiris em seu artigo: trata-se de aproximar "o olho do objeto, apoiando-se na convicção de que tal movimento conduz efetivamente a outra maneira de ver" (p. 2I4). Ela acompanha assim o artigo de Leiris, descrevendo as inúmeras referências que o compõem; destacam-se daí as lembranças de infância, os experimentos surrealistas, a sociabilidade da vanguarda artística parisiense, o novo projeto museológico empreendido pelo Museu de Etnografia, o fascínio do exotismo, as leituras e os cursos etnográficos. A viagem interior de Leiris não deixa de ser ao mesmo tempo exterior, na medida em que põe em movimento um repertório de ideias sobre a África então em circulação na capital francesa; em contrapartida, ao estabelecer o foco sobre si mesmo, tal viagem possui um profundo sentido autobiográfico, que orientou quase tudo o que Leiris escreveu daí em diante. Delineia-se assim o significado que a viagem tem para ele: "Longe de funcionar apenas como meio de recuperação do tempo passado, a autobiografia apresenta-se como um operador discursivo que visa organizar o presente e controlar o futuro" (p. 240). A despeito da inexequibilidade plena desse projeto, que $A$ África fantasma, escrito durante a missão, logo tornará patente, Leiris não o abandonou jamais.

Esse procedimento de redução da escala analítica, que não é senão um close-up, para continuar com a metáfora visual, possui um limite bem definido: tudo o que se encontra fora de seu enquadramento permanece-lhe alheio. A grande vantagem desse recurso consiste certamente em furtar-se aos critérios e às explicações por demais gerais, que homogeneízam fenômenos muito distintos. No entanto, muitas vezes os elementos externos ao enquadramento, ligados a processos mais amplos, exercem um efeito decisivo no objeto estudado; dificilmente eles deixam de se manifestar no objeto, mas o close-up pode muito bem ofuscá-los. Freyre, por exemplo, viajou por Portugal e suas colônias a convite do governo Salazar; apesar de ser parte constituinte dessa viagem, Peixoto dedica-lhe somente uma curta nota (p. I69, nota I), enfatizando na verdade o ponto de vista escolhido por Freyre. Essa não é uma crítica de cunho ideológico, sempre cômoda de ser feita com um distanciamento temporal, mas de uma observação metodológica; trata-se de refletir sobre um aspecto importante da viagem de Freyre que conduz fatalmente para além do enquadramento escolhido. O close-up mostra-se particularmente útil na apresentação de uma perspectiva específica, daí seu emprego bem acertado para acompanhar os itinerários particulares dos viajantes nesse livro e, dessa forma, projetar uma nova forma de olhar sobre eles. O problema advém da dificuldade de ultrapassar essa perspectiva; nesse caso, o recurso etnográfico habitual ao ponto de vista nativo poderia, por exemplo, ser contrabalançado simultaneamente pela leitura a contrapelo proposta por Walter Benjamin (I994). No caso de Leiris, seu repertório de ideias sobre a África estava irremediavelmente vinculado ao colonialismo; mas seria equivocado reduzir aquele a este, pois o projeto etnológico do qual Leiris fazia parte, que atribuía aos costumes nativos uma lógica própria, diferente, porém não inferior à ocidental, era sem dúvida 
progressista para a época, não obstante sua relação profunda com o colonialismo. Portanto, o enquadramento do close-up define-se idealmente por uma leitura a um só tempo a favor e contra a perspectiva do objeto, o que permite, de um lado, considerar seus critérios próprios, de outro, ultrapassá-los.

A despeito dessa objeção, não há dúvida alguma que $A$ viagem como vocação ilumine aspectos imprevistos das obras dos autores analisados, resultando numa mirada inovadora e instigante, que não apenas supera o conhecimento preexistente como ainda valoriza o potencial explicativo da produção de figuras renomadas dentro do campo das ciências sociais, no Brasil e alhures. Não obstante a copiosa fortuna crítica e a consagração amealhada por cada um deles, a autora revisita-os a partir de ângulos pouco explorados, extraindo do conteúdo de suas intervenções leituras dotadas de argúcia e sensibilidade interpretativa. Assim, ao radicalizar em A viagem como vocação o movimento reflexivo iniciado em sua tese de doutorado, Peixoto revela integralmente sua postura desafeita às perspectivas totalizadoras e às ideias bem estabelecidas; ela assume, vale dizer, sua maneira indisciplinada de fazer pesquisa.

\section{SOBRE OS AUTORES}

RODRIGO RAMASSOTE é pós-doutorando em Antropologia Social na Universidade de São Paulo (USP), com estágio de pesquisa no Department of Anthropology at University of South Florida (USF) e bolsista da Fapesp.

E-mail: ramassote@hotmail.com

LUÍS FELIPE SOBRAL é pós-doutorando em Antropologia Social na USP e bolsista da Fapesp; foi pesquisador convidado na École des Hautes Études en Sciences Sociales (EHESS).

E-mail: lf_sobral@yahoo.com

\section{REFERÊNCIAS}

BENJAMIN, Walter. Sobre o conceito de história. In: . Magia e técnica, arte e política. Ensaios sobre literatura e história da cultura. São Paulo: Brasiliense, I994, p. 222-232.

LEIRIS, Michel. L'œil de l'ethnographe (Ā propos de la Mission Dakar-Djibouti). Documents. Archéologie, beaux-arts, ethnographie, variétés, Paris, $2^{\circ}$ ano, n. 7, p. 404-4I4, I930 (ed. fac-similar, Paris: Jean-Michel Place, I99I). . L’Afrique fantôme. Paris: Gallimard, I934. 
LEVI-STRAUSS, Claude. Tristes tropiques. Paris: Plon, I955.

MASSI, Fernanda Peixoto. Franceses e norte-americanos nas ciências sociais brasileiras. In: MICELI, Sergio (Org.). História das ciências sociais no Brasil. São Paulo: Idesp/Vértice/Finep, I989, v. I, p. 4I0-459. . Estrangeiros no Brasil: a Missão Francesa na Universidade de São Paulo. Dissertação (Mestrado em Antropologia Social). Instituto de Filosofia e Ciências Humanas, Universidade Estadual de Campinas, I99I.

. O nativo e o narrativo. Os trópicos de Lévi-Strauss e a África de Michel Leiris. Novos Estudos, São Paulo, n. 33, p. I87-I98, I992.

PEIXOTO, Fernanda. Lévi-Strauss no Brasil: a formação do etnólogo. Mana - Estudos de Antropologia Social, Rio de Janeiro, v. 4, n. I, p. 79-I07, I998.

PEIXOTO, Fernanda Arêas. Diálogos brasileiros: uma análise da obra de Roger Bastide. São Paulo: Editora da Universidade de São Paulo, 2000.

PEIXOTO, Fernanda A. A viagem como vocação. Antropologia e literatura na obra de Michel Leiris. In: LEIRIS, Michel. A África fantasma. São Paulo: Cosac Naify, 2007, p. I9-33. 